\title{
EDITORIAL
}

\section{Parasitic zoonoses in PResent day Europe}

\section{Belgrade, 18-20 ${ }^{\text {th }}$ November 2009}

A

$\mathrm{n}$ international conference, "Parasitic zoonoses in present day Europe", was held from the $18^{\text {th }}$ to the $20^{\text {th }}$ of November 2009 in Belgrade. This conference was organized at the closure of the SERBPARZOON project, a European Union FP6 project aimed at reinforcing the capacities of the Serbian Centre for Parasitic Zoonoses (SCPZ) at the Institute for Medical Research (IMR) in Belgrade, by the training and the mobility of scientists, by granting young scientists and upgrading the lab equipment and facilities. The project (2007-2009) was a concerted effort of medical doctors, veterinarians, and biologists, to lead the SCPZ to become a focal point for the surveillance and control of parasitic zoonoses at both the national and regional levels. The Conference brought together some of the most distinguished experts from the EU and the region with the SCPZ personnel and Serbian professionals in the field.

The scientific program included about 50 oral communications, consisting of both state-of-the-art lectures on issues such as trichinellosis, toxoplasmosis and vector-borne diseases, and presentations of current epidemiological and epizootiological data, along with relevant current basic research in this field.

In addition to providing valuable insight into the current status of these diseases in Europe and particularly in its South-East, participation of researchers from eleven EU and non-EU European countries allowed the Conference to serve as a networking forum to create new and enhance existing partnerships, with a view to further scientific cooperation. The geographic position of Southeast Europe as a region between Mediterranean and continental Europe, makes it a privileged area to observe ongoing and anticipate emerging zoonotic infections. That is why the Belgrade conference was important not only as a forum for the exchange of knowledge and ideas but also as a show case into the achieved capacity level of parasitologists in the region of Southeast Europe, certainly very important for both public and animal health and joint research efforts.

In appreciation of both the significance of South-East Europe for the observation and control of parasitic diseases, and the achieved level in parasitology research in the region, the board of PARASITE - Journal of the French Society of Parasitology - proposed to the conference organizers to publish some of the reports presented during these days and invited the Association of South-Eastern and Eastern European Parasitologists (SEEP) to support the editorial efforts of PARASITE. In the coming issues, a number of selected articles from this conference will appear, with a view of presenting the current state of epidemiology and research on the main parasitic zoonoses in Europe, particularly in its South-East. We hope that these articles will contribute to reinforce ties between European scientists.

Olgica Djurković-Djaković \& Jean Dupouy-Camet (invited guest editors)
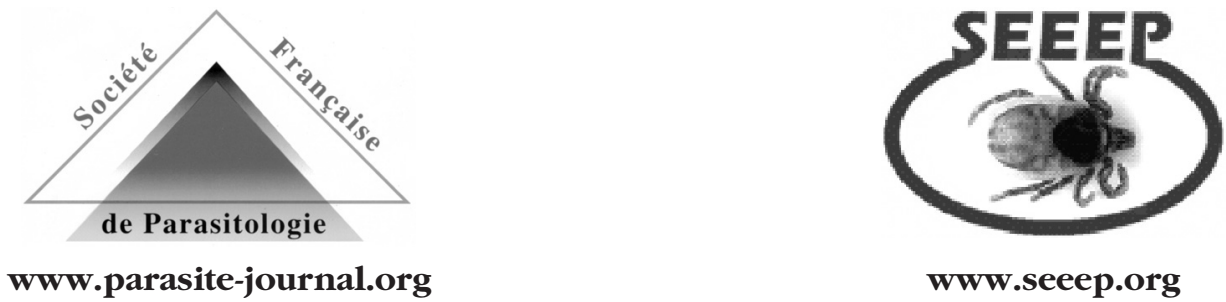